Provided for non-commercial research and education use. Not for reproduction, distribution or commercial use.

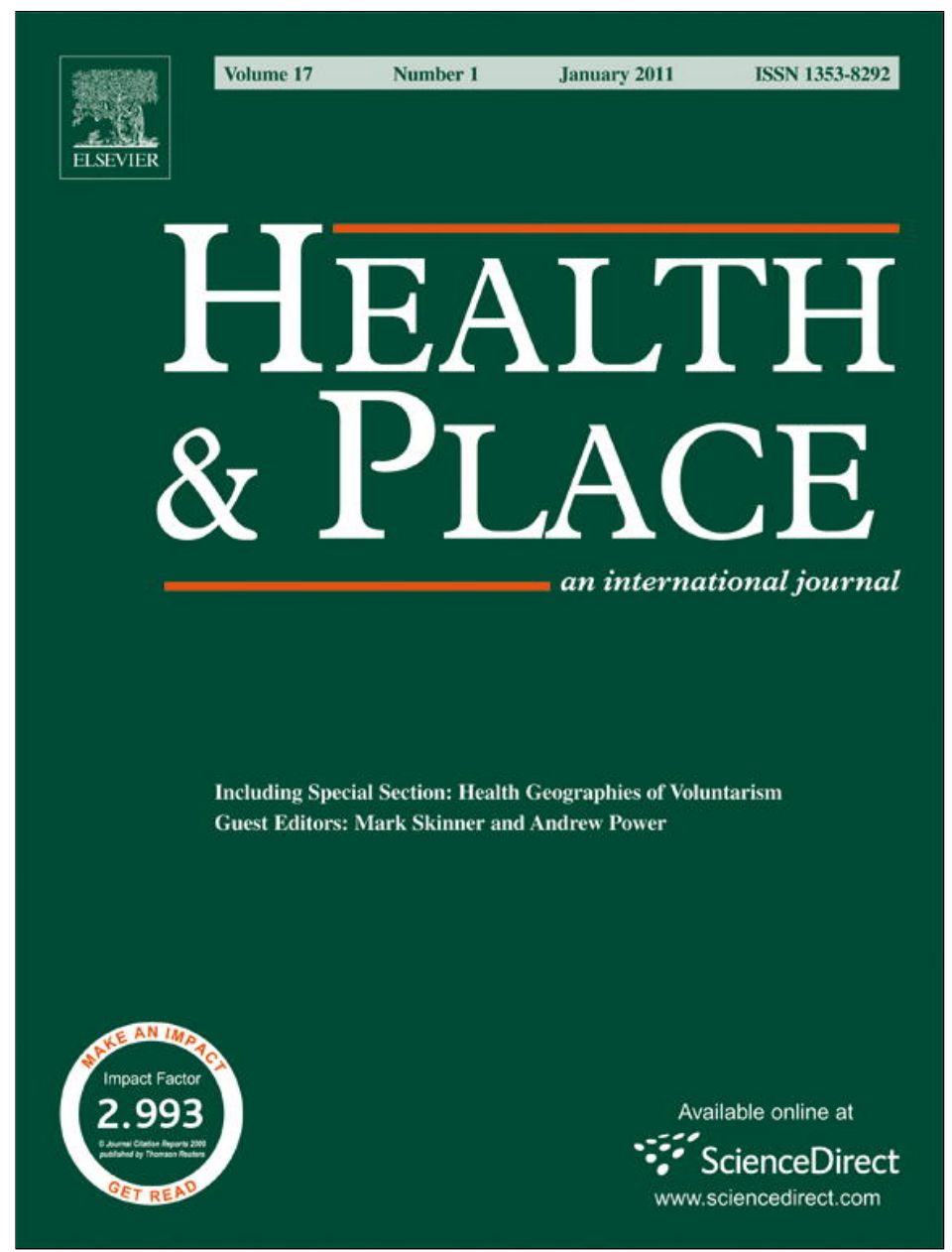

This article appeared in a journal published by Elsevier. The attached copy is furnished to the author for internal non-commercial research and education use, including for instruction at the authors institution and sharing with colleagues.

Other uses, including reproduction and distribution, or selling or licensing copies, or posting to personal, institutional or third party websites are prohibited.

In most cases authors are permitted to post their version of the article (e.g. in Word or Tex form) to their personal website or institutional repository. Authors requiring further information regarding Elsevier's archiving and manuscript policies are encouraged to visit:

http://www.elsevier.com/copyright 


\title{
Perceived environmental risk as a predictor of teenage motherhood in a British population
}

\author{
Sarah E. Johns* \\ School of Anthropology and Conservation, Marlowe Building, University of Kent, Canterbury, Kent CT2 7NR, UK
}

\section{A R T I C L E I N F O}

\section{Article history:}

Received 3 November 2009

Received in revised form

2 September 2010

Accepted 9 September 2010

Available online 18 September 2010

\section{Keywords:}

Teenage motherhood

Risk

Perception

Pregnancy

Adolescent

Neighbourhood effects

\begin{abstract}
A B S T R A C T
Previous studies have shown that strong relationships exist between deprived environments and teenage motherhood. However, such studies have predominantly identified deprivation using neighbourhood-wide measures of socio-economic status. Few studies of teenage parenthood have examined how individuals perceive their environment and the importance of this perception on reproductive behaviour and timing. Using data collected from a sample of women living the county of Gloucestershire, UK, this paper explores the predictive value of two methods of assessing the environment: (1) the structural component-deprivation at the neighbourhood level and (2) the individual's subjective experience of her pre-pregnancy environment, when examining how the wider environmental context can influence the decision of becoming a teenage mother. The results indicate that a woman's perception of her neighbourhood of residence at the time she conceived, her perceived environmental risk, may be a more discriminating predictor of teenage motherhood than deprivation measured by ward economic and deprivation indicators.
\end{abstract}

(c) 2010 Elsevier Ltd. All rights reserved.

\section{Introduction}

It has been well documented that child and adolescent development and well-being is influenced by area of residence (Leventhal and Brooks-Gunn, 2000) and that women who give birth as teenagers often live in neighbourhoods that are classified as deprived. Research has indicated that teenage pregnancy and motherhood correlate with the socioeconomic status of, or social deprivation in, the area of residence (Brewster, 1994a, 1994b; Brewster et al., 1993; Brooks-Gunn et al., 1993; Crane, 1991; Garlick et al., 1993; Hogan and Kitagawa, 1985; Kirby et al., 2001; Singh, 1986) and that where a woman lives may be related to her chance of conceiving before she turns twenty (Diamond et al., 1999). Research exploring the influence of neighbourhoods on pregnancy timing has typically linked effects such as neighbourhood-wide measures of socio-economic status, access to education, and poor career prospects to teenage motherhood, often focussing on the experiences of deprived African-American adolescents (Brewster, 1994a; Brooks-Gunn et al., 1993; Crane, 1991; Hogan and Kitagawa, 1985).

The United States has the highest rate of teenage conceptions and births in the developed world, at 52.1 births per 1000 women aged 15-19, while countries such as Korea, Japan, Switzerland and the Netherlands all have rates lower than 7 births per 1000

\footnotetext{
* Tel.: +44 1227823 232; fax: +44 1227827289 .

E-mail address: s.e.johns@kent.ac.uk
}

women (UNICEF, 2001). It has been argued that the difference between nations on this measure reflects income inequality: where there is greater disparity between rich and poor, teenage births are more common (Wilkinson and Pickett, 2009). In other words teenage births are more common in unequal societies. It is well established that African-American teenagers, who have higher rates of poverty, higher unemployment rates and high rates of serious illness when compared to 'white' American women (McAdoo, 2006), have a birth rate twice that of their white counterparts ( 84 per 1000 vs. 45 per 1000 UNICEF, 2001). Teenage births are also more common among ethnic minorities in other developed countries: in the Netherlands the majority of the small number of teenage births are to ethnic minority immigrants (UNICEF, 2001). This may in part be due to the social and economic exclusion that such communities face (reflecting overall inequality).

The United Kingdom, where this study was conducted, has the highest rate of teenage pregnancy (and motherhood) in Western Europe (Bradley-Stevenson and Mumford, 2007; UNICEF, 2001; Wellings et al., 1999; Westall, 1997). In 2001 there were 30.8 births per 1000 women between the ages of 15 and 19 (UNICEF, 2001). Recent data taken across England and Wales (May 2010) show that although there has been a general decline in the rate of teenage conceptions since 1998, categorised by the British government as conceptions to females under the age of 18 and under the age of 16 , the rate has remained above 40 per thousand in the under 18 year old category and above 7 per thousand in the under 16 year old category. Overall, in England and Wales, 
there were 635,901 live births in 1998 and 708,711 live births in 2008, an increase of 72,810 (Teenage Pregnancy Unit, 2010).

Across the UK rates of teenage pregnancy and motherhood are highest in industrial and mining areas, ports, and in urban environments (teenage births 43 per 1000 15-19 year olds in areas classified as 'Ports and Industries') while lowest in areas classed as growing or prosperous ( $\sim 11$ births per $100015-19$ year olds) (Armitage, 1997; Botting et al., 1998). Women living in the most deprived neighbourhood in England had their first child at a younger age than women from affluent areas (Nettle, 2010). This suggests that area of residence is a significant factor in births to British teenage mothers, and indicates the importance of the area where a young woman lived at the time she conceived (Wellings et al., 1999).

Such research appears to demonstrate that geographical location, in addition to individual characteristics, is important in determining the occurrence of teenage pregnancy and parenting. Similarly, such 'neighbourhood effects' (for a thorough review see Jencks and Mayer, 1990) have been considered important in the explanation of, among others, poor educational attainment (Garner and Raudenbush, 1991), child abuse and maltreatment (Coulton et al., 1999), and crime and delinquency (Sampson and Groves, 1989).

Although the study of neighbourhood effects in relation to particular outcomes can assist policy makers in concentrating efforts on specific geographical locations, there has been criticism of using this approach in the context of teenage pregnancy, as well as more broadly. Identifying such effects over and above individual characteristics can be extremely difficult. The characteristics of a neighbourhood may, for example, be due to the fact that families with similar backgrounds tend to live in the same area (Overman, 2002). The data sets which have been most often used to examine neighbourhood effects on teenage fertility also rarely contain measures of any potential intervening mechanisms (South and Baumer, 2000). Furthermore, examinations into the relative contributions of neighbourhood and family measures on developmental outcomes of individuals typically define neighbourhood characteristics purely by aggregate characteristics from census-level data and ignore individuals' actual experiences of their neighbourhoods (Elliott et al., 2006; Geronimus et al., 1996; MacIntyre et al., 1993; O'Neil et al., 2001; Wilson, 1991a). It has been strongly suggested that "the emergent social organisation and culture of the neighbourhood" (Elliott et al., 2006, p. 279) is much more important than overall socioeconomic status when trying to explain individual variation within local environments. In relation specifically to teenage motherhood, McCulloch (2001) demonstrated that the association between living in a deprived area of Britain and teenage motherhood was due to the personal disadvantage that comes from living in such an area, and that it was this disadvantage, not an effect attributable to neighbourhood, that was the more significant determinant of teenage motherhood (McCulloch, 2001). It has also been suggested that even if women from socioeconomically deprived neighbourhoods are more likely to have children as teenagers, there is still no understanding as to why groups of women from disadvantaged areas would share a belief that teenage motherhood is a positive or desirable outcome (South and Baumer, 2000).

In light of these difficulties, the research approach of examining neighbourhood deprivation indices and linking them to local teenage pregnancy rates, though highlighting a potential relationship, may not be the best method to explore how individual women are influenced in their sexual and reproductive decisionmaking by their neighbourhood's characteristics. The associations between area of residence and personal characteristics, and between these and subsequent behaviour (McCulloch, 2001) suggest that a more profitable approach to exploring the links between deprived environments and teenage motherhood may be to investigate respondents' subjective perceptions about the area in which they live. This approach is also recommended by South and Baumer (2000) who believe that more direct real and perceived measures will help explain community effects on behavioural outcomes in adolescents.

There is an extensive research paradigm suggesting that individual perception of the environmental context is a key variable influencing behaviour (Anthony and Nicotera, 2008; Baxter and Eyles, 1999; Earls et al., 1994; Kingston et al., 2009; Leventhal and Brooks-Gunn, 2000; Sooman and MacIntyre, 1995; Spencer, 2001; Walsh-Daneshmandi and MacLachlan, 2000; Wilson, 1991b). One aspect of this work is the investigation of perception of risk in, and/or overall quality of, the local environment and how this relates to heath behaviours, including mental and physical well-being (Baum et al., 2009; Carter et al., 2009; Chandola, 2001; Cho et al., 2005; Christie-Mizell et al., 2003; Collins et al., 1998; Gary et al., 2007; Lumeng et al., 2006; Poortinga et al., 2008; Sooman and MacIntyre, 1995; Wen et al., 2006) and smoking (Siahpush et al., 2006). For example, Cho et al. (2005) found that individuals who were dissatisfied with their neighbourhoods had poor emotional health. Relationships between feeling unsafe in a neighbourhood and general health assessment have also been explored (Baum et al., 2009; Chandola, 2001), as has the role subjective neighbourhood assessment plays in determining psychological well-being specifically among women (Carter et al., 2009; Christie-Mizell et al., 2003).

A subset of this work has specifically focused on the role that individual environmental perception has in shaping adolescent mental health and related behaviours (Aneshensel and Sucoff, 1996; Buysse, 1997; Lambert et al., 2004; Rasmussen et al., 2004; Schwab-Stone et al., 1995; Sellström and Bremberg, 2006; Upchurch et al., 1999). Aneshensel and Sucoff (1996) classified graffiti, crime, violence, and drug use as threatening conditions when asking adolescents about their environments, and suggested that such conditions should be considered as ambient environmental hazards that directly contribute to antisocial conduct and mental health problems, while Schwab-Stone et al. (1995) linked antisocial behaviour to how safe, or unsafe, adolescents felt in their residential neighbourhood.

Together these studies strongly suggest that individual perceptions do matter, and need to be included in research investigating behaviour and the role of wider environmental contexts and furthermore, that individual perception of neighbourhood quality and risk is a more salient, and potentially more accurate, predictor of health, well-being, and social behaviour of both adolescents and adults than objective and structural measures. An individual's assessment of the area in which they live appears to affect, either consciously or unconsciously, the life decisions they make and how they behave.

Individual perceptions of local environment are also directly related to both sexual behaviour and pregnancy outcomes. Teenagers who perceived their environments as threatening entered sexual relationships at earlier ages (Upchurch et al., 1999), while women who rated their environments unfavourably on a variety of measures, such as community support, had babies of lower birth-weight (Auger et al., 2008; Buka et al., 2003; Collins et al., 1998). Such findings are especially intriguing as they suggest a direct link between individual perceptions of the local environment and specific reproductive health outcomes and behaviours.

To date, however, no research has specifically examined the relationship between perceptions of the neighbourhood and teenage motherhood. This is surprising given the number of studies which link teenage pregnancy and motherhood to the 
general neighbourhood context. Human sexual behaviour and reproductive decision making is undeniably complex, and although numerous factors may contribute to the occurrence of teenage motherhood, a successful understanding of the role played by the environment in this outcome requires appropriate measures of the environment. The inclusion of individual environmental perception measures during explorations of such behaviours should lead to a more precise understanding as to why such strong relationships exist between place of residence and the timing of reproductive events.

Within this study, instead of focusing solely on the economic attributes/deprivation of a neighbourhood (the objective structural component of the environment: Aneshensel and Sucoff, 1996) as a predictor of teenage motherhood, the predictive value of young women's perceptions of their pre-pregnancy neighbourhood environments (the subjective experiential component: Aneshensel and Sucoff, 1996) is also explored, with the aim of testing whether subjective views of the environment might be more useful than typical economic-status and deprivation descriptors as a measure of the environmental influence on reproductive behaviour.

\section{Data and methods}

\subsection{Study population}

Data were taken from a retrospective case-control study of teenage motherhood, collected by self-completion postal questionnaire in the county of Gloucestershire, which is situated in the South-West of England. Within Gloucestershire, every woman who had given birth for the first time within the four years prior to the study date, whilst a teenager (12-19 years), was contacted by post, as were a randomly selected equal number of women who had given birth to their first child between the ages of 20 and 27 years. A case-control design was used because it allowed for the comparison of two groups of women who had already experienced their first birth and therefore took into account that women's perceptions may have been influenced by the experience of becoming a mother. Ethical clearance for this project was obtained from the South West Local Research Ethics Committee and all responses were held in the strictest confidence. Full details on participants and procedures can be found elsewhere (Johns, 2003).

Both the sample and the location of the study were well suited for investigating the predictive value of both the objective (economic deprivation) and subjective (perceived) environments on teenage motherhood. The data came from a contemporary sample of women, all of whom had given birth to their first child within the 4 year period before the questionnaire was received. Response rates for a postal questionnaire were acceptable with a response rate of $41.7 \%$ ( $n=332$ ) for women who had given birth as teenagers, and $58.3 \%(n=465)$ for women had given birth after the age of 19 . Respondents were typically long-term residents of the county, having lived in Gloucestershire for an average of 220.18 months $(S D=101.7$, median $=240$, range $=2-384$ months $)$, or approximately 18 years at the time the questionnaire was received. Respondents were also evenly distributed geographically, indicating that no one area of the county was severely underrepresented by non-response. Teenage and non-teenage mother respondents did not vary systematically from each other in their geographic distribution and, overall, respondents had a similar geographic distribution to those who chose not to respond. Questions about race/ethnicity could not be asked of the study sample, due to ethical guidelines, but results from the 2001 UK census reveal that the county is very homogenous in terms of ethnic background-the total proportion of people from non-white ethnic groups in Gloucestershire is only 2.8\%, which is small compared to England and Wales as a whole (9.1\%) (Gloucestershire County Council, 2006).

Although Gloucestershire is a county often regarded as having few social problems, many difficulties, such as being socially isolated, can arise for residents who live in rural areas on low incomes. Such a possibility has been largely ignored with most studies of deprivation and teenage pregnancy and motherhood focussing on large urban environments rather than predominantly rural, affluent counties like Gloucestershire with hidden pockets of both rural and urban deprivation (Roberts, 1998). The existence of deprivation and social problems within the county (around the time respondents' conceptions occurred) can be seen when factors such as health and crime are examined; some districts scored worse than the national average on these indicators. Two of these districts, Gloucester and Cheltenham, were placed in the worst half of the Department of the Environment's Index of Local Conditions, with rankings of 138 and 156 out of 366, respectively, where the worst district is ranked 1. It was also recognised that, in 1998, parts of urban Gloucestershire, specifically the city of Gloucester, had problems such as crime and drug addiction, equivalent to those of larger cities (Roberts, 1998).

\subsection{Environmental measures}

\subsubsection{Structural component}

Information about a woman's ward of residence when she became pregnant was determined for a sub-sample of women ( $n=369,46.3 \%$ of the total). This sub-sample consisted of the respondents for whom complete postcode information at the time of conception was known. Postcodes were matched to wards using the Updated UK Lookup-Tables, available through the Manchester Information \& Associated Services data-set service at the University of Manchester (http://convert.mimas.ac.uk; Simpson, 2001). ${ }^{1} \mathrm{~A}$ ward is the base unit for all United Kingdom administrative geography, and is an electoral subdivision of the local authority. At the time data was collected there were 142 wards in the county of Gloucestershire, all of which had distinct boundaries. The use of wards is highly appropriate for this study, given that they are small geographical areas of fewer than (in Gloucestershire) 3000 residents (Gloucestershire County Council, 2002). When neighbourhood characteristics are studied using larger geographic boundaries too much variation within the defined boundary, and too little variation between the areas of interest, exists. This reduces precision and makes it difficult to determine the importance of particular variables on the outcome of interest (Sellström and Bremberg, 2006).

The deprivation level of each ward was determined by using the average gross household weekly income amount for each ward (ward socioeconomic status, hereafter ward SES), the Childhood Poverty Index (hereafter CPI), and the Index of Multiple Deprivation for England 2000 (hereafter IMD). These measures were obtained in August 2009 from the official UK Neighbourhood Statistics Service web site organised by the Office for National Statistics (ONS, 2008). They were chosen as the most useful tools with which to measure neighbourhood deprivation in this study, primarily because they examine poverty at the ward level. Furthermore, they are more up to date than previous indices (for example the Index of Local Deprivation 1998, which was mostly based on 1991 Census data), and have results that are

\footnotetext{
${ }^{1}$ Continuation and further development of this project now found at http:// geoconvert.mimas.ac.uk/
} 
available online (ONS, 2009). More details about the IMD and the CPI can be found in the Department of the Environment, Transport and the Regions (DETR) (2000) document.

The measure of household income, rounded to the nearest $£ 10$, was compiled by the ONS using data from the 1991 UK census, Inland Revenue and benefit claimant data, and the 1998/1999 Survey of Family Resources, and therefore is a reasonable assessment of ward household income at the time to which the study relates. The measure of childhood poverty was taken from the index created in 2000 by the DETR (as was) as a supplement to the IMD. The CPI ward score refers to the proportion of children under the age of 16 living in benefit-reliant families for each ward. For example, a childhood poverty score of 20.8 indicates that $20.8 \%$ of the children in that ward live in income deprived households.

The Index of Multiple Deprivation (IMD) 2000, commissioned by the DETR, is a combination of 33 deprivation indicators that form six domains of deprivation at the ward level (defined by administrative boundaries as of April 1998), with each domain weighted and standardised to create a multiple deprivation score for every ward in England. The IMD ward scores, unlike the measure obtained from the CPI, do not represent a proportion of the deprived ward population and cannot be used as a cardinal measure (although have often been treated as such, cf. Woolley et al., 2006). Therefore, to use this measure appropriately in parametric regression analyses, and for ease of interpretation, the IMD ward scores for the sample in this study were divided into quartiles, with the 1 st quartile representing the least deprived wards and the 4th quartile representing the most deprived wards in the study.

\subsubsection{Subjective experiential component}

To measure how an individual perceived the quality of her environment at the time she conceived, the respondents were asked to complete a section of 12 items, integrated into a larger self-completion questionnaire, that asked about the dangers in and general 'atmosphere' of, their residential area (Table 1). These items dealt with ambient hazards and social cohesion of their residential area and allowed for consideration of, and potential comparison between, positive (support) and negative (risk to self) neighbourhood factors. Although the subjective component measure was designed for this study, questions were modified from existing sources that have attempted to evaluate individual perceptions in both the support and risk domains (Aneshensel and Sucoff, 1996; Moore and Chase-Lansdale, 2001; Siahpush et al., 2006; Sooman and MacIntyre, 1995; Steptoe and Feldman, 2001). Questions were scored on a Likert-type scale where 5 equalled Strongly Agree and 1 equalled Strongly Disagree. It was anticipated that the 12 items would relate to the perceived level of risk that a neighbourhood posed for each individual.

A principal-components method of factor extraction was used on the 12 questionnaire items. Missing values were replaced by the mean and varimax rotation was used (Kaiser, 1958). Use of oblique rotation was also explored, but did not alter any results. For ease of interpretation the orthogonal measures were therefore used in model building (Klein, 2005). The Kaiser-Meyer-Olkin (KMO) measure of sampling adequacy was also examined to determine whether principal components analysis was suitable for data reduction in this instance. Factor scores using the regression method were created for each individual. Examination of the scree plot and eigenvalues indicated there were two underlying factors both with eigenvalues over 1 (Kaiser Criterion). These factors could be readily interpreted, with the items loading into each being of a similar theme, and accounted for $68.63 \%$ of the variance. All 12 items loaded at values greater than $\times 0.50$,
Table 1

Varimax rotated component matrix from PCA of the items related to perception of the pre-pregnancy environment. Greatest item loading values are shown.

\begin{tabular}{|c|c|c|}
\hline \multirow[t]{2}{*}{ Items } & \multicolumn{2}{|l|}{ Factor } \\
\hline & $\begin{array}{l}\text { Perceived } \\
\text { environmental } \\
\text { risk }\end{array}$ & $\begin{array}{l}\text { Perceived } \\
\text { community } \\
\text { support }\end{array}$ \\
\hline $\begin{array}{l}\text { Item 1: The area I lived did not feel safe to } \\
\text { me }\end{array}$ & 0.705 & \\
\hline $\begin{array}{l}\text { Item 2: I did not feel safe walking alone in } \\
\text { the area during the day }\end{array}$ & 0.635 & \\
\hline $\begin{array}{l}\text { Item 3: I did not feel safe walking alone in } \\
\text { the area after dark. }\end{array}$ & 0.568 & \\
\hline Item 4: The area was not a nice place to live & 0.703 & \\
\hline $\begin{array}{l}\text { Item 5: The area was not a nice place for } \\
\text { children to grow up. }\end{array}$ & 0.680 & \\
\hline $\begin{array}{l}\text { Item 6: I was scared to be alone in my house } \\
\text { because of the area I was living in }\end{array}$ & 0.711 & \\
\hline Item 7: Crime was a problem in the area & 0.845 & \\
\hline $\begin{array}{l}\text { Item 8: Vandalism was a problem in the } \\
\text { area }\end{array}$ & 0.835 & \\
\hline $\begin{array}{l}\text { Item 9: There were problems (such as noise, } \\
\text { abuse, or crime) with my neighbours in } \\
\text { the area }\end{array}$ & 0.829 & \\
\hline $\begin{array}{l}\text { Item 10: I felt threatened by violence in the } \\
\text { area }\end{array}$ & 0.816 & \\
\hline Item 11: I felt I was part of a community. & & -0.858 \\
\hline $\begin{array}{l}\text { Item 12: In general I would say that when I } \\
\text { got pregnant I lived in an area where } \\
\text { people helped each other out }\end{array}$ & & -0.825 \\
\hline
\end{tabular}

which is considered the minimum significant loading score (Hair et al., 1998). Even though PCA analysis was only attempted on 12 items in this instance, the KMO measure of sampling adequacy (0.92) attested to the appropriateness of using PCA in this case. The two factors were orthogonal (uncorrelated). Specific items and their greatest loading values can be found in Table 1 .

The first factor obtained from the PCA (eigenvalue $=7.10$, $59.42 \%$ of the total variance accounted for, $n=10$ items loading above 0.50 on this factor, $\bar{x}=2.06, \mathrm{SD}=0.86$ ) contained all the items that asked a respondent, from a pessimistic standpoint, how they felt about the area where they lived when they conceived. These 10 items all appeared to measure a respondent's subjective opinion about how dangerous and risky her local environment was at the time she when became pregnant. This component was labelled perceived environmental risk. Cronbach's alpha coefficient was 0.93 , which indicates extremely high inter-item reliability.

The second factor obtained from the PCA (eigenvalue $=1.12$, $9.39 \%$ of the variance, $n=2, \bar{x}=3.14, \mathrm{SD}=0.95$ ) contained the two questions from the original 12 item scale that asked about the respondent's integration into her community at the time when she became pregnant and how involved the community members were with one other. This factor was labelled perceived community support. Cronbach's alpha coefficient for this factor was 0.77 .

\subsubsection{Familial component}

To determine the relative importance of the environment, and more specifically to evaluate whether the subjective component is a more useful measure than the structural component when other, known, predictors of teenage motherhood are considered, the environmental measures were evaluated in the presence of two additional independent variables, family stress and family structure during childhood, to control for the effect of the preconception family environment. It has been demonstrated that the family environment and relationships within families have strong impacts on reproductive timing and the occurrence of teenage motherhood (Belsky et al., 1991; Garfinkel and 
Mclanahan, 1986; Kiernan and Hobcraft, 1997; Wu and Martinson, 1993). Although a number of additional variables could have been included at this point, two strong predictor variables of family environment are sufficient, especially as the family stress variable is an aggregate measure; additional variables would lead to a more complex, and potentially meaningless, model and would make it more difficult to directly address the hypothesis of this study.

The level of family stress experienced by a respondent was determined using the Family Stress Scale (Mikach and Bailey, 1999). The 12-item Family Stress Scale was originally designed to determine whether women who reported higher numbers of sexual partners had stressful childhood memories, and to assess family-life during childhood. Answers to the items presented as statements were given on a five-point scale where 1 equalled Strongly Agree and 5 equalled Strongly Disagree, where higher scores indicated a more stressful family situation (Cronbach's alpha $=0.91$ ).

To ascertain childhood family structure the sample were asked with whom they had lived the most before the age of 12 . A list of 13 possible family types was included and there was an 'Other' category listed that could be checked if none of the family types listed fitted that particular individual. Age 12 was chosen as it was the youngest possible age of any contacted individual. As the family structure variable was categorical, the responses were recoded into the larger categories of living with both father and mother (biological or adopted) and living in some other family type. This methodology has been used in previous studies to determine childhood family structure (Amato et al., 1995; Mclanahan and Sandefur, 1994).

\subsection{Analytic strategy}

The dependent variable (motherhood status) was categorised as a binary variable, Teenage Mother (women who had given birth before the age of 20), and Non-teenage Mother (women who had given birth between 20 and 27), as this reflects the case-control nature of the data collection. As the dependent variable was discreet, an ordinary least squares linear regression model could be anticipated to be heteroscedastic and predict probability values beyond the $(1,0)$ range. Thus, binary logistic regression models ( 6 in total) were used for analysis. This is the appropriate multivariate technique for the estimation of a binary outcome in a case-control study such as this, when the predictor variables are either continuous or categorical. It allowed for the calculation of the relative risk of being a teenage mother through the calculation of an odds ratio (Hosmer and Lemeshow, 1989; Kleinbaum, 1994). Data were analysed using SPSS version 16 . For all five models the odds ratios (OR) and 95\% confidence intervals (CI) were calculated. Case-deletion statistics were analysed to ensure that no single individual was unduly affecting the models' outcomes.

Multicollinearity between variables was assessed to determine their appropriateness for use in additive models. There were no serious inter-correlations between any of the variables used in the analyses described below. For example, Ward SES and perceived environmental risk were only moderately correlated $\left(r_{s}=-0.38\right.$, $n=369, p<0.001$ two-tailed), and the variance inflation factor was found to be acceptable (VIF=1.67) (Miles and Shevlin, 2001).

Models 1-3 tested whether structural components of the environment significantly predicted teenage motherhood, using ward SES, the CPI, and the IMD as the independent (predictor) variables. In Model 4, the independent variables entered into analysis were the factor scores for the measure of perceived environmental risk and the measure of perceived community support obtained in the previously described principal components analysis. These represent potential measures of the subjective component of the environment. Model 5 tested the predictive value of the respondents' family circumstances using a measure of family stress and the respondents' family structure at age 12. Significant measures from Models 1-5 were then entered into an additive binary logistic model (Model 6) to examine which were the most significant predictors of teenage motherhood when the effects of the other variables in the model were partialled out.

\section{Results}

369 women living in 112 distinct wards were included in the analysis. Of these, 123 had given birth while they were teenagers and 246 had given birth between the ages of 20 and 27. The mean age at first birth was 22.9 years $(S D=4.02$, range $=13.92-28.00)$. The average gross household weekly income by ward for the sample was $£ 455.50$ ( $S D=79.38$, range $=£ 260-710$ ). Just over $80 \%$ of respondents had lived primarily with both parents before the age of 12 , with $19.2 \%$ having grown up in some other family structure. The mean time that had elapsed between the birth of their child and the receipt of the questionnaire was 2.27 years $(\mathrm{SD}=1.16$, range $=0.50-4.41)$, and there was no significant difference between teenage and non-teenage mothers on this measure. Therefore, it was assumed that there would be minimal difference in the recall of events and feelings between the two groups of mothers.

Teenage motherhood was predicted separately by each of the structural measures (Table 2). Living in a ward with a low SES at the time pregnancy occurred, determined by mean ward income level, increased a woman's odds of being a teenage mother (Model $\left.1: n=369, \chi^{2}=14.29, \mathrm{df}=1, p<0.001\right)$. For every unit of increase in the gross weekly household income of a particular ward, a woman's odds of being a teenage mother decreased by 0.99 .

Residing in a ward with high childhood poverty at the time pregnancy occurred also was found to predict a woman's odds of being a teenage mother (Model 2: $n=369, \chi^{2}=16.15, \mathrm{df}=1$, $p<0.001$ ). For every unit of increase in the proportion of children living in poverty in a particular ward, a woman's odds of being a teenage mother increased by 1.03 or $3 \%$.

Teenage motherhood was also predicted by the overall deprivation of a ward (Model 3: $n=369, \chi^{2}=18.54, \mathrm{df}=3$, $p<0.001)$. For example, respondents who lived in the most deprived wards (4th quartile) were $239 \%(O R=3.39)$ more likely to be teenage mothers when compared to respondents who lived in the least deprived wards (1st quartile).

The odds of being a teenage mother increased if a respondent lived in an area she believed to be dangerous at the time she became pregnant (Model 4: $n=369, \chi^{2}=37.21, \mathrm{df}=2, p<0.001$ ). Only one of the two variables entered into the model was significant. The measure of perceived community support was not a significant predictor of teenage motherhood. For every unit of increase $(+1)$ of perceived environmental risk, however, the odds of a woman being a teenage mother increased by a factor of 2.06 or $106 \%$ (Table 2 ).

Model 5 examined the two measures of the family environment $\left(n=369, \chi^{2}=13.89, \mathrm{df}=2, p=0.001\right)$. Family stress was the only significant predictor of teenage motherhood. For every unit increase in family stress score, the odds of being a teenage mother increased by $44 \%(\mathrm{OR}=1.44$, Table 2$)$.

Combining the significant predictors into a single additive model showed that perceived environmental risk was the only significant predictor of teenage motherhood when controlling for the effects of ward SES, the CPI score, IMD by quartile and family stress ( $\mathrm{OR}=1.73,95 \% \mathrm{CI} 1.31-2.29, p<0.001$, Table 2 ). The model was significant (Model 6: $n=369, \chi^{2}=44.02, \mathrm{df}=7, p<0.001$ ) and 
Table 2

Results of logistic regression models comparing environmental predictors of teenage motherhood.

\begin{tabular}{|c|c|c|c|c|c|}
\hline & $\beta$ & Std. error & OR & $95 \% \mathrm{CI}$ & $P$ \\
\hline \multicolumn{6}{|l|}{ Model 1} \\
\hline Ward SES & -0.006 & 0.002 & 0.99 & $\begin{array}{l}0.991- \\
0.997\end{array}$ & $<0.001$ \\
\hline Constant & 1.801 & 0.686 & & & \\
\hline \multicolumn{6}{|l|}{ Model 2} \\
\hline CPI & 0.032 & 0.008 & 1.03 & $1.01-1.04$ & $<0.001$ \\
\hline Constant & -1.538 & 0.247 & & & \\
\hline \multicolumn{6}{|l|}{ Model 3} \\
\hline \multicolumn{6}{|l|}{$I M D$} \\
\hline $\begin{array}{c}\text { 1st Quartile } \\
\text { (base category) }\end{array}$ & \multicolumn{4}{|c|}{ (base category) } & 0.001 \\
\hline 2nd Quartile & 0.286 & 0.342 & 1.33 & $0.68-2.60$ & NS \\
\hline 3rd Quartile & 0.879 & 0.328 & 2.40 & $1.26-4.57$ & $<0.01$ \\
\hline 4th Quartile & 1.223 & 0.324 & 3.39 & $1.80-6.1$ & $<0.001$ \\
\hline Constant & -1.312 & 0.246 & & & \\
\hline \multicolumn{6}{|l|}{ Model 4} \\
\hline Perceived environmental risk & 0.726 & 0.128 & 2.06 & $1.60-2.65$ & $<0.001$ \\
\hline Perceived community support & 0.187 & 0.123 & 1.20 & $0.94-1.53$ & NS \\
\hline Constant & -0.642 & 0.118 & & & \\
\hline \multicolumn{6}{|l|}{ Model 5} \\
\hline Family stress & 0.365 & 0.136 & 1.44 & $1.10-1.88$ & 0.007 \\
\hline \multicolumn{6}{|l|}{ Childhood family structure } \\
\hline Living with both parents & & & 1.00 & & NS \\
\hline Other family situation & 0.423 & 0.289 & 1.52 & $0.86-2.69$ & NS \\
\hline Constant & -1.675 & 0.342 & & & \\
\hline \multicolumn{6}{|l|}{ Model 6} \\
\hline Perceived environmental risk & 0.550 & 0.143 & 1.73 & $1.31-2.29$ & $<0.001$ \\
\hline Family stress & 0.271 & 0.139 & 1.31 & $0.99-1.72$ & 0.052 \\
\hline Ward SES & 0.000 & 0.003 & 1.00 & $0.99-1.00$ & NS \\
\hline$C P I$ & 0.002 & 0.014 & 1.31 & $0.97-1.02$ & NS \\
\hline \multicolumn{6}{|l|}{ IMD } \\
\hline \multicolumn{6}{|l|}{ (base category) } \\
\hline 2nd Quartile & 0.028 & 0.380 & 1.02 & $0.48-2.16$ & NS \\
\hline 3rd Quartile & 0.538 & 0.458 & 1.71 & $0.69-4.20$ & NS \\
\hline 4th Quartile & 0.486 & 0.558 & 1.62 & $0.54-4.85$ & NS \\
\hline Constant & -1.621 & 1.583 & & & \\
\hline
\end{tabular}

$\beta=$ logit coefficient, $P=$ significance $\leq 0.05, \quad$ OR=odds ratio, $95 \% \quad \mathrm{CI}=95 \%$ confidence interval.

over $71 \%$ of the responses could be classified under a 0.5 cut-off. For every unit of increase in perceived environmental risk the odds of being a teenage mother increased by a factor of 1.73 or $73 \%$. Family stress was just not significant at the 0.05 level in this model (Table 2). The odds of being a teenage mother under different levels of perceived environmental risk when controlling for the structural and familial components of the environment are shown in Fig. 1.

\section{Discussion}

This study found that teenage motherhood was predicted by a woman's subjective experience of risk in her environment, and that this was a more discriminating predictor than either economic indicators of environmental deprivation or measures of family stress and stability. The constructed variable perceived environmental risk was the only significant predictor of teenage motherhood when the effects of the other variables in the models were partialled out. Earlier motherhood, at least in Gloucestershire, may not therefore be directly related to neighbourhood wide deprivation in the pre-pregnancy area of residence. Rather, it appears to be better predicted by subjective experiences of the area of residence. Although these results provide support for the hypothesis (for example Brooks-Gunn et al., 1993; Crane, 1991;

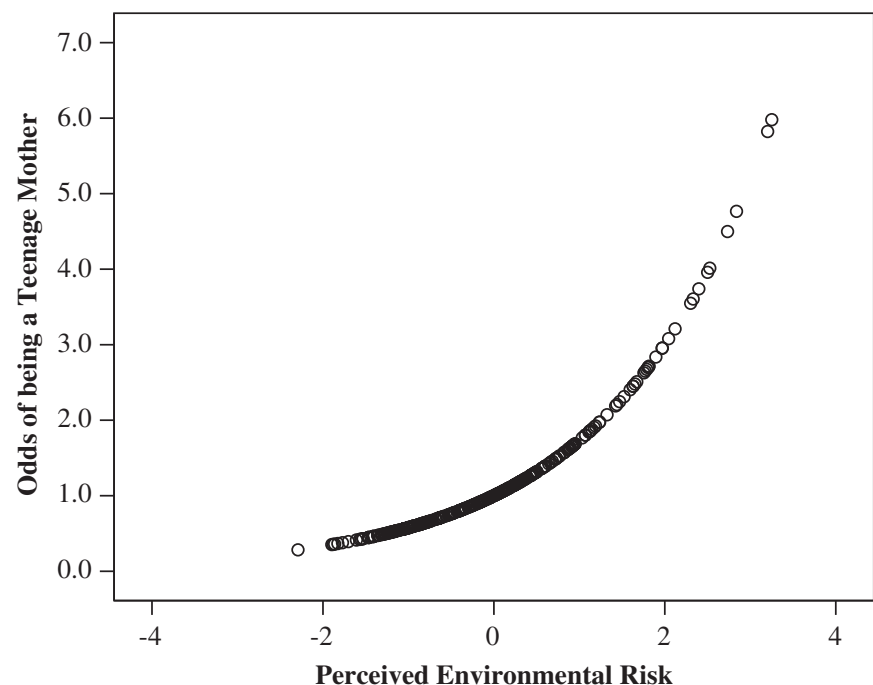

Fig. 1. Odds of being a teenage mother under different levels of perceived environmental risk $(n=369)$ when controlling for ward SES and family stress. Odds are calculated by the following: $\log$ odds $=(\beta \times$ perceived environmental risk $)$, odds $=\exp ^{\text {(log odds) }}$

Hogan and Kitagawa, 1985) that women were more likely to be teenage mothers if they lived in relatively deprived environments at the time they became pregnant, they indicate that this may be better understood as a result of individual perceptions of the environment (potentially including salient information provided by the structural factors) rather than neighbourhood effects based on deprivation indicators. This concurs with the results presented by McCulloch (2001), who showed that personal circumstances, rather than area of residence, predicted teenage childbearing.

These results suggest that the perception of the wider neighbourhood environment, rather than the overall level of economic deprivation, potentially in conjunction with the more narrow confines of the home may influence pregnancy timing. This finding is similar to results reported by Upchurch et al. (1999) that the structural effect of the neighbourhood was nonsignificant for the timing of sexual debut when family characteristics and a measure of the experiential neighbourhood were included in the model. In Upchurch et al.'s (1999) study, girls who believed they lived in more hazardous neighbourhoods had higher rates of early sex; here, girls with similar beliefs were more likely to be teenage mothers.

\subsection{Approach}

This study took into account aggregate area characteristics, as is the norm in neighbourhood effect studies of behaviour, while also accounted for individuals' experiences of their environment. This approach is quite different to those studies that use only a general area deprivation measure to examine neighbourhood or environmental effects on behaviour, and is important because of prior difficulties in identifying true neighbourhood effects over those of individual characteristics (O'Neil et al., 2001; South and Baumer, 2000). A measure of subjective environmental assessment is not often used in examinations of the effect that area of residence has on adolescent sexual behaviours and reproduction, so its inclusion in the models in this paper offers an innovative and novel approach to examining wider environmental influences on teenage motherhood. The results, in conjunction with those of Upchurch et al. (1999), show the importance of accounting for individuals' subjective perceptions of their neighbourhood 


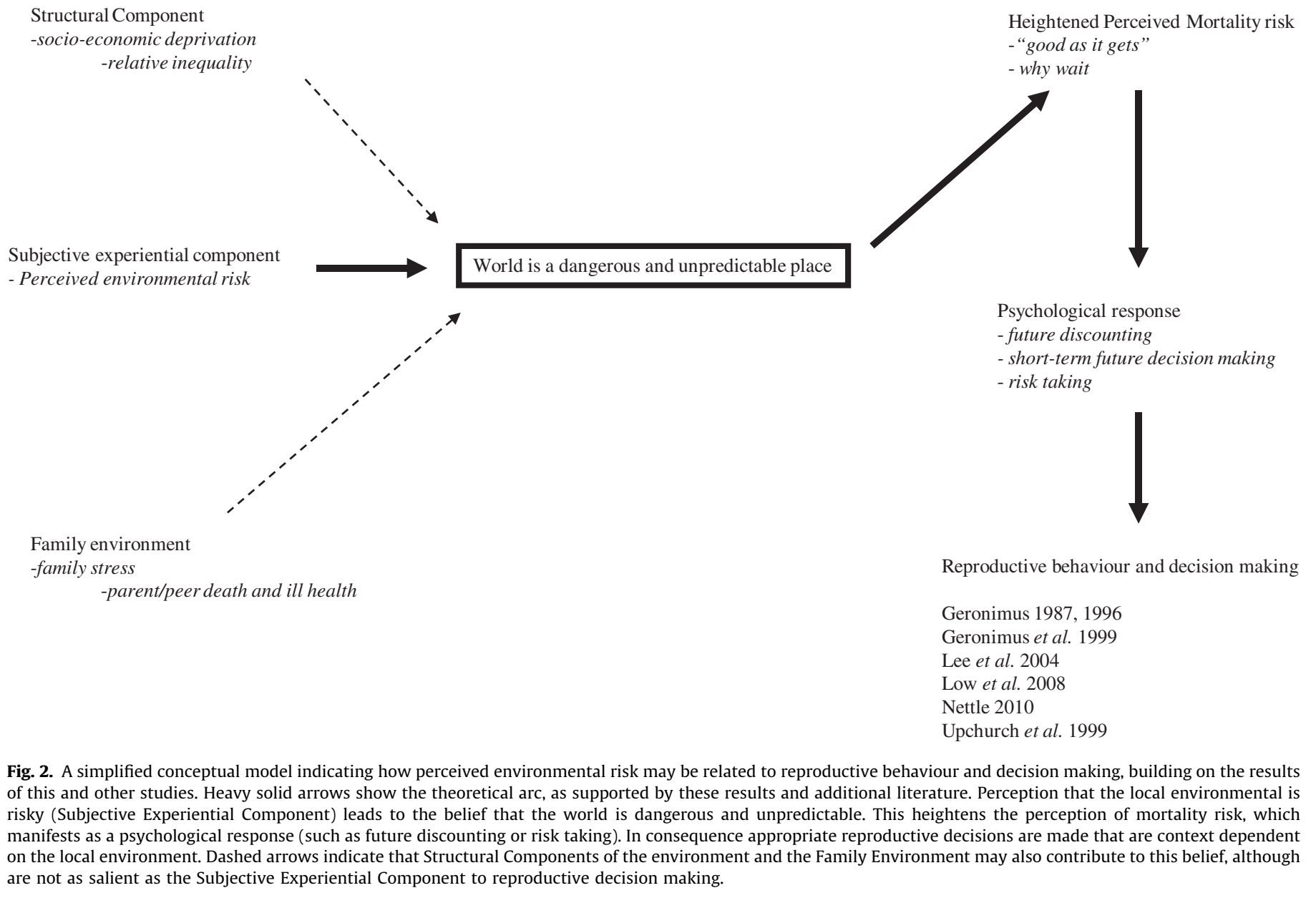

environment when examining teenage motherhood and potential antecedents.

The deprivation indicators (ward SES, CPI and IMD) performed poorly as predictors of teenage motherhood in this study when other components of the environment were considered. Such indicators may not properly reflect the aspects of the environment which relate to an earlier age at first birth. This further illustrates the importance of asking respondents to rate their perceptions of their environments, as aggregate measures of overall deprivation that primarily deal with economic hardship may not necessarily give a clear indication of how an individual actually perceives and responds to living in such environments. They may also not have sufficient precision to be used as proxy measures of day-to-day difficulties encountered by an area's residents. For example, according to data from Family Expenditure Survey 1997-2001 the average gross weekly household income of the ward of residence for this study was $£ 455$ (approximately $£ 23,660$ per year), which is $£ 6$ pounds per week more than the average gross weekly household income for the South-western region of England as a whole ( $£ 449$ per week) during the same period (ONS, 2009). Even for the teenage mothers, the average gross weekly household income was $£ 433$, which is only $£ 16$ below the regional average (ONS, 2009). All the women in this study, at least according to average ward socioeconomic status, were therefore not substantially more economically deprived at the time they became pregnant when compared to the average household resident from South-west England. The items that went into developing the perceived environmental risk score, however, dealt with danger indicators and actual risk to self (ambient hazards), rather than economic deprivation, and specifically included questions about feeling scared or feeling threatened in the neighbourhood. Living in a (perceived as) 'risky' environment as opposed to a relatively 'deprived' neighbourhood appears to be the better predictor of teenage motherhood. This suggests that even individuals living in moderately deprived environments relative to areas of prosperity can still feel threatened and 'at risk', and sense that their area of residence is a dangerous place to live.

\subsection{Risk and reproduction}

Although there have been some findings in a similar vein to the results presented here, for example adolescents with a negative view of their neighbourhood are also more likely to be involved in antisocial behaviour (Seidman et al., 1998) and start sexual relationships at an earlier age (Upchurch et al., 1999), the results of this study suggest that women who lived in environments that they perceived as detrimental to their person prior to becoming pregnant may have reacted by reproducing at a younger age. Fig. 2 provides a simplified conceptual model indicating how perceived environmental risk may be related to reproductive behaviour and decision making, accounting for the results of this analysis and results from other appropriate literature.

Benoit (1997) touches on these ideas when providing a case study of a teenager from a violent neighbourhood who had witnessed the murder of an acquaintance. The young woman reported that she was considering becoming pregnant as she felt 'her life could be truncated by a bullet in the violent neighbourhood in which she lived,' and that if she was killed she would have 
at least left a child behind to carry on (Benoit, 1997, p. 407). It has also been proposed that a heightened sense of risk may have farreaching implications on how young people view and make decisions about their futures (Halpern-Felsher and Millstein, 2002). Other work conducted in inner-city environments found that urban teenage mothers did not expect to live to an old age as they had negative views about their future, were often a part of an economic underclass with higher mortality rates and poorer health than the general population (Geronimus, 1996). In this view, early motherhood is a rational (but not necessarily conscious) reproductive strategy that may be a response to living in an unstable environment where there are fewer guarantees of experiencing a successful future (Geronimus, 1987, 1996; Geronimus et al., 1999; Nettle, 2010). Becoming a teenage mother could therefore be a strategy pursued by women who do not see long-term futures for themselves. Recent research by Lee et al. (2004) supports these theoretical assumptions, with teenage girls from deprived environments believing that their current situation is as "good as it gets", and that this attitude may, in part, explain pro-natalist/anti-abortion sentiment in deprived areas (Lee et al., 2004).

The perception of living in a risky environment may have an effect on temporal outlook, and by extension, life decisions. Individuals who live in families or neighbourhoods that are unpredictable or dangerous may come to view the world as a dangerous unpredictable place (Hill et al., 1997). For example, if an individual lives in a neighbourhood where they or some of their peers have been attacked or threatened, then discounting the future and perceiving the environment as unstable and dangerous may be a normal reaction for that individual. Anticipation of a brief future under such circumstances could inspire short-term views or risk-taking when decisions are made (Hill et al., 1997; Wilson and Daly, 1997). It has even been suggested that lower life expectancy should be directly related to the timing of first reproduction (Low et al., 2008). If human reproductive timings are influenced by the level of risk in the environment it may be that it is the perception of this risk, rather than its absolute level, that influences behaviour and so the timing of reproductive events (Fig. 2).

There are a few potential limitations of the findings presented in this paper. First, it is unfortunate that appropriate postcode information was not available for all respondents. A majority of those respondents who did not answer the question in full indicated they did so, not because of concern over privacy issues, but because they simply could not remember their previous, time-of-conception postcode. Therefore the sub-sample consisted of women who had either not moved since conception or who had good re-call of their previous address. Furthermore, there were no major or salient differences between the respondents for whom conception postcode data was known and for those where residence information could not be ascertained. For example, teenage women included and excluded from the analysis did not significantly differ in their age when their baby was born, their family stress score, their perceived environmental risk score, their previous number of pregnancies (that had not resulted in live birth), and their time spent living in the county. This suggests that the results from the sub-sample are generalisable to the entire sample of questionnaire respondents. Second, it was not possible to include any objective measure of risk (e.g. crime statistics) as this information was not available for individual wards. Crime statistics for the district level would have not provided enough precision for meaningful analysis. This may be an area for future research. Finally, it is unclear how generalisable these results are to other populations. The South-west of England is extremely deprived in parts, but this level of deprivation may not match that found in, for example, inner-city environments in the United
States. However, perceived environmental risk still appears to be a strong predictor of pregnancy timing, even in this less deprived situation. It is possible that in particularly dangerous, urban environments risk perception could be even more influential, especially in areas where life expectancy is severely compromised through violence.

In conclusion, the results presented in this paper indicate that measures of perception may offer increased precision than measures of actual deprivation for studies seeking to understand teenagers' reproductive decisions in particular environments. The inclusion of the measure perceived environmental risk in models predicting teenage motherhood is a new and rewarding approach. Perceived levels of risk and danger to the self appear to be important factors in reproductive decision-making, yet few other studies have examined this relationship. Future research exploring any relationship between adolescent childbearing and the residential environment may have to consider the inclusion of a risk perception measure. The collection of additional data in environments more hazardous and unstable than urban Gloucestershire would also allow this intriguing approach to be developed further.

\section{Acknowledgements}

I thank M. Shaw, K. Jones, M. Powell and D. Harvey, M. Keating and staff from the East Gloucestershire NHS trust, C. Bodkin and staff from the Severn NHS trust, and the Gloucestershire Health Authority (as was) for assistance in undertaking this research. I must also thank N.E. Newton-Fisher for his helpful comments. This work was funded by the ORS Awards Scheme, the University of Bristol, and from a grant received by Gloucestershire's Teenage Pregnancy Strategy from the Department of Health's Teenage Pregnancy Implementation Fund. These funders were not involved in the writing and submission of this paper. Finally, I must acknowledge the mothers of Gloucestershire who kindly agreed to participate in this research. A preliminary version of this paper was presented at the British Society for Population Studies (BSPS) Conference, held at the University of Kent.

\section{References}

Amato, P.R., Loomis, L.S., Booth, A., 1995. Parental divorce, marital conflict, and offspring well-being during early adulthood. Social Forces 73, 895-915.

Aneshensel, C.S., Sucoff, C.A. 1996. The neighbourhood context of adolescent mental health. Journal of Health and Social Behavior 37, 293-310.

Anthony, E.K., Nicotera, N., 2008. Youth perceptions of neighborhood hassles and resources: a mixed method analysis. Children and Youth Services Review 30, 1246-1255.

Armitage, B., 1997. Variations in fertility between different types of local area. Population Trends 87, 20-28.

Auger, N., Daniel, M., Platt, R.W., Wu, Y.Q., Luo, Z.C., Choiniere, R., 2008. Association between perceived security of the neighbourhood and small-for-gestationalage birth. Paediatric and Perinatal Epidemiology 22, 467-477.

Baum, F.E., Ziersch, A.M., Zhang, G., Osborne, K., 2009. Do perceived neighbourhood cohesion and safety contribute to neighbourhood differences in health? Health \& Place 15 925-934.

Baxter, J., Eyles, J., 1999. The utility of in-depth interviews for studying the meaning of environmental risk. Professional Geographer 51, 307-320.

Belsky, J., Steinberg, L., Draper, P., 1991. Childhood experience, interpersonal development, and reproductive strategy: an evolutionary theory of socialization. Child Development 62, 647-670

Benoit, M.B., 1997. The role of psychological factors on teenagers who become parents out-of-wedlock. Children and Youth Services Review 19, 401-413.

Botting, B., Rosato, M., Wood, R., 1998. Teenage mothers and the health of their children. Population Trends 93, 19-28.

Bradley-Stevenson, C., Mumford, J., 2007. Adolescent sexual health. Paediatrics and Child Health 17, 474-479.

Brewster, K.L., 1994a. Neighborhood context and the transition to sexual activity among young black women. Demography 31,603-614.

Brewster, K.L., 1994b. Race differences in sexual activity among adolescent women: the role of neighborhood characteristics. American Sociological Review 59, 408-424. 
Brewster, K.L., Billy, J.O.G., Grady, W.R., 1993. Social context and adolescent behavior: the impact of community on the transition to sexual activity. Social Forces 71, 713-740.

Brooks-Gunn, J., Duncan, G.J., Klebanov, P.K., Sealand, N., 1993. Do neighborhoods influence child and adolescent development? American Journal of Sociology 99 353-395.

Buka, S.L., Brennan, R.T., Rich-Edwards, J.W., Raudenbush, S.W., Earls, F., 2003. Neighborhood support and the birth weight of urban infants. American Journal of Epidemiology. 157, 1-8.

Buysse, W.H., 1997. Behavior problems and relationships with family and peers during adolescence. Journal of Adolescence 20, 645-659.

Carter, S., Williams, M., Paterson, J., Iusitini, L., 2009. Do perceptions of neighbourhood problems contribute to maternal health? findings from the Pacific Islands families study. Health \& Place 15, 622-630.

Chandola, T., 2001. The fear of crime and area differences in health. Health \& Place 7, 105-116.

Cho, Y., Park, G.-S., Echevarria-Cruz, S., 2005. Perceived neighborhood characteristics and the health of adult Koreans. Social Science \& Medicine 60, 1285-1297.

Christie-Mizell, C.A., Carr Steelman, L.C., Stewart, J., 2003. Seeing their surroundings: the effects of neighborhood setting and race on maternal distress. Social Science Research 32, 402-428.

Collins, J.W., David, R.J., Symons, R., Handler, A., Wall, S., Andes, S., 1998. African American mothers' perception of their residential environment, stressful life events, and very low birthweight. Epidemiology 9, 286-289.

Coulton, C.J., Korbin, J.E., Su, M., 1999. Neighborhoods and child maltreatment: a multi-level study. Child Abuse and Neglect 23, 1019-1040.

Crane, J., 1991. The epidemic theory of ghettos and neighborhood effects on dropping out and teenage pregnancy. American Journal of Sociology 96, 1226-1259.

Department of the Environment, Transport and the Regions (DETR), 2000. Indices of Deprivation 2000: Regeneration research summary no. 31. The Stationery Office, London.

Diamond, I., Clements, S., Stone, N., Ingham, R., 1999. Spatial variation in teenage conceptions in South and West England. Journal of the Royal Statistical Society, A 162, 273-289.

Earls, F., Mcguire, J., Shay, S., 1994. Evaluating a community intervention to reduce the risk of child abuse: methodological strategies in conducting neighborhood surveys. Child Abuse \& Neglect 18, 473-485.

Elliott, D.S., Menard, S., Rankin, B., Elliott, A., Huizinga, D., Wilson, W.J., 2006. Good Kids from Bad Neighborhoods: Successful Development in Social Context. Cambridge University Press, New York City.

Garfinkel, I., Mclanahan, S.S., 1986. Single Mothers and their Children: A New American Dilemma. Urban Institute, Washington, DC.

Garlick, R., Ineichen, B., Hudson, F., 1993. The UPA score and teenage pregnancy. Public Health 107, 135-139.

Garner, C.L., Raudenbush, S.W., 1991. Neighborhood effects on educational attainment: a multilevel analysis. Sociology of Education 64, 251-262.

Gary, T.L., Stark, S.A., Laveist, T.A., 2007. Neighborhood characteristics and mental health among African Americans and Whites living in a racially integrated urban community. Health \& Place 13, 569-575.

Geronimus, A.T., 1987. On teenage childbearing and neonatal mortality in the United States. Population and Development Review 13, 245-279.

Geronimus, A.T., 1996. What teen mothers know. Human Nature 7, 323-352.

Geronimus, A.T., Bound, J., Neidert, L.J., 1996. On the validity of using census geocode characteristics to proxy individual socioeconomic characteristics. Journal of the American Statistical Association 91, 529-537.

Geronimus, A.T., Bound, J., Waidmann, T.A., 1999. Health inequality and population variation in fertility-timing. Social Science \& Medicine 49, 1623-1636.

Gloucestershire County Council, 2002. Mid-year population estimates for Gloucestershire and districts. Retrieved August 2009 from <http://www Gloucestershire.Gov.Uk/index.Cfm?Articleid=5209>.

Gloucestershire County Council (The Research Team), 2006. Housing and Households in Gloucestershire. Gloucestershire County Council. Gloucestershire, UK.

Hair Jr., J.F., Anderson, R.E., Tatham, R.L., Black, W.C., 1998. Multivariate Data Analysis-Fifth edition. Prentice Hall, New Jersey.

Halpern-Felsher, B.L., Millstein, S.G., 2002. The effects of terrorism on teens' perceptions of dying: the new world is riskier than ever. Journal of Adolescent Health 30, 308-311.

Hill, E.M., Ross, L.T., Low, B.S., 1997. The role of future unpredictability in human risk taking. Human Nature 8, 287-325.

Hogan, D.P., Kitagawa, E.M., 1985. The impact of social status, family structure, and neighborhood on the fertility of black adolescents. American Journal of Sociology 90, 825-852.

Hosmer, D.W., Lemeshow, S., 1989. Applied Logistic Regression. John Wiley \& Sons Inc, New York.

Jencks, C., Mayer, S.E., 1990. The social consequences of growing up in a poor neighborhood. In: Lynn, L.E., Mcgeary, M.G.H. (Eds.), Inner-City Poverty in the United States. National Academy Press, Washington, DC, pp. 111-186.

Johns, S.E., 2003. Environmental Risk and the Evolutionary Psychology of Teenage Motherhood. University of Bristol, Bristol.

Kaiser, H.F., 1958. The varimax criterion of analytic rotation in factor analysis. Psychometrika 23, 187-200.

Kiernan, K.E., Hobcraft, J., 1997. Parental divorce during childhood: age at first intercourse, partnership and parenthood. Population Studies 51, 41-55.

Kingston, B., Huizinga, D., Elliott, D.S., 2009. A test of social disorganization theory in high-risk urban neighborhoods. Youth Society 41, 53-79.
Kirby, D., Coyle, K., Gould, J.B., 2001. Manifestations of poverty and birthrates among young teenagers in California zip code areas. Family Planning Perspectives 33, 63-69.

Klein, T.J.B., 2005. Psychological Testing: A Practical Approach to Design and Evaluation. Sage Publications, Thousand Oaks, CA

Kleinbaum, D.G., 1994. Logistic Regression: A Self-learning Text. Springer-Verlag, New York.

Lambert, S.F., Brown, T.L., Phillips, C.M., Ialongo, N.S., 2004. The relationship between perceptions of neighborhood characteristics and substance use among urban African American adolescents. American Journal of Community Psychology 34, 205-218.

Lee, E. Clements, S., Ingham, R., Stone, N., 2004. A matter of choice? Explaining national variation in teenage abortion and motherhood. The Joseph Rowntree Foundation. York Publishing Services Ltd., York.

Leventhal, T., Brooks-Gunn, J., 2000. The neighborhoods they live in: the effects of neighborhood residence on child and adolescent outcomes. Psychological Bulletin 126, 309-337.

Low, B.S., Hazel, A., Parker, N., Welch, K.B., 2008. Influences on women's reproductive lives: unexpected ecological underpinnings. Cross-Cultura Research 42, 201-219.

Lumeng, J.C., Appugliese, D., Cabral, H.J., Bradley, R.H., Zuckerman, B., 2006 Neighborhood safety and overweight status in children. Archives of Pediatrics \& Adolescent Medicine 160, 25-31.

McAdoo, H.P., 2006. Black Families, 4th Ed. Sage Publications, Newbury Park, CA.

Macintyre, S., Maciver, S., Sooman, A., 1993. Area, class and health: should we be focusing on places or people? Journal of Social Policy 22 213-234.

Mcculloch, A., 2001. Teenage childbearing in Great Britain and the spatial concentration of poverty households. Journal of Epidemiology and Community Health 55, 16-23.

Mclanahan, S.S., Sandefur, G., 1994. Growing Up with a Single Parent: What Hurts, What Helps. Harvard University Press, Cambridge, MA.

Mikach, S.M., Bailey, J.M., 1999. What distinguishes women with unusually high numbers of sex partners? Evolution and Human Behavior 20 141-150.

Miles, J., Shevlin, M., 2001. Applying Regression and Correlation. Sage Publications, London.

Moore, M.R., Chase-Lansdale, P.L., 2001. Sexual intercourse and pregnancy among African American girls in high-poverty neighborhoods: the role of family and perceived community environment. Journal of Marriage and Family 63, 1146-1157.

Nettle, D., 2010. Dying young and living fast: variation in life history across English neighbourhoods. Behavioral Ecology 21, 387-395

O'Neil, R., Parke, R.D., Mcdowell, D.J., 2001. Objective and subjective features of children's neighborhoods: relations to parental regulatory strategies and children's social competence. Journal of Applied Developmental Psychology 22, 135-155

ONS, Office for National Statistics, 2008. Neighbourhood statistics service. Office for National Statistics, London. Retrieved August 2009 from 〈http://www. neighbourhood.statistics.gov.uk/dissemination/ $>$.

ONS, Office For National Statistics, 2009. Family Expenditure Survey (FES), Household income: By source, 1998/2001: Regional trends 37. Office for National Statistics, London. Retrieved October 2009 from <http://www statistics.gov.uk/STATBASE/expodata/spreadsheets/D5998.xls $\rangle$.

Overman, H.G., 2002. Neighbourhood effects in large and small areas. Urban Studies 39, 117-130.

Poortinga, W., Dunstan, F.D., Fone, D.L., 2008. Neighbourhood deprivation and selfrated health: the role of perceptions of the neighbourhood and of housing problems. Health \& Place 14, 562-575.

Rasmussen, A., Aber, M.S., Bhana, A., 2004. Adolescent coping and neighborhood violence: perceptions, exposure, and urban youths efforts to deal with danger. American Journal of Community Psychology 33, 61-75.

Roberts, T. 1998. A Profile of Poverty in Gloucestershire: Working Together to Make a Difference. Environment Department, Gloucestershire County Council, Gloucestershire, UK.

Sampson, R.J., Groves, W.B., 1989. Community structure and crime: testing socialdisorganization theory. American Journal of Sociology 94, 774-802.

Schwab-Stone, M.E., Ayers, T.S., Kaspow, W., Voyce, C., Barone, C., Shriver, T. Weissberg, R.P., 1995. No safe haven: a study of violence exposure in an urban community. Journal of the American Academy of Child and Adolescent Psychiatry 34, 1343-1352.

Seidman, E., Yoshikawa, H., Roberts, A., Chesir-Teran, D., Allen, L., Friedman, J.L. Aber, J.L., 1998. Structural and experiential neighborhood contexts, developmental stage and antisocial behavior among urban adolescents in poverty. Development and Psychopathology 10, 259-281.

Sellström, E., Bremberg, S., 2006. Review article: the significance of neighbourhood context to child and adolescent health and well-being: a systematic review of multilevel studies. Scandinavian Journal of Public Health 34 544-554.

Siahpush, M., Borland, R., Taylor, J., Singh, G.K., Ansari, Z., Serraglio, A., 2006. The association of smoking with perception of income inequality, relative material well-being, and social capital. Social Science \& Medicine 63, 2801-2812.

Simpson, L., 2001. Updated UK Area Masterfiles: Final Report to the UK Economic and Social Research Council. Centre for Census and Survey Research, University of Manchester, Manchester.

Singh, S., 1986. Adolescent pregnancy in the United States: an interstate analysis. Family Planning Perspectives 18, 210-220. 
Sooman, A., MacIntyre, S., 1995. Health and perceptions of the local environment in socially contrasting neighbourhoods in Glasgow. Health \& Place 1, 15-26.

South, S.J., Baumer, E.P., 2000. Deciphering community and race effects on adolescent premarital childbearing. Social Focus 78, 1379-1408.

Spencer, M.B., 2001. Resiliency and fragility factors associated with the contextual experiences of low resource urban African American male youth and families. In: Booth, A., Crouter, A. (Eds.), Does it Take a Village? Community Effects in Children, Adolescents and Families. Lawrence Erlbaum Associates, Mahwah, NJ, pp. 51-77.

Steptoe, A., Feldman, P.J., 2001. Neighborhood problems as sources of chronic stress: development of a measure of neighborhood problems, and associations with socioeconomic status and health. Annals of Behavioral Medicine 23, 177-185.

Teenage Pregnancy Unit, 2010. Under 18 Conceptions Statistics 1998-2008. Retrieved July 2010 from 〈http://www.dcsf.gov.uk/everychildmatters/resour ces-and-practice/IG00200/ $\rangle$.

UNICEF, 2001. A League Table of Teenage Births in Rich Nations, Innocenti Report Card no. 3 (vol. 3). UNICEF Innocenti Research Centre, Florence.

Upchurch, D.M., Aneshensal, C.S., Sucoff, C.A., Levy-Storms, L., 1999. Neighborhood and family contexts of adolescent sexual activity. Journal of Marriage and the Family 61, 920-933.

Walsh-Daneshmandi, A., Maclachlan, M., 2000. Environmental risk to the self: factor analysis and development of subscales for the environmental appraisal inventory (EAI) with an Irish sample. Journal of Environmental Psychology 20, 141-149.
Wellings, K., Wadsworth, J., Johnson, A., Field, J., Macdowell, W., 1999. Teenage fertility and life chances. Reviews of Reproduction 4, 184-190.

Wen, M. Hawkley, L.C. Cacioppo, JT., 2006. Objective and perceived neighborhood environment, individual SES and psychosocial factors, and self-rated health: an analysis of older adults in Cook County, Illinois. Social Science \& Medicine 63, 2575-2590.

Westall, J., 1997. Poor education linked with teenage pregnancies. British Medical Journal 314, 535

Wilkinson, R., Pickett, K., 2009. The Spirit Level: Why More Equal Societies Almost Always do Better. Allen Lane, London.

Wilson, M., Daly, M., 1997. Life expectancy, economic inequality, homicide, and reproductive timing in Chicago neighbourhoods. British Medical Journal 314, 1271-1274.

Wilson, W.J., 1991a. Public policy research and the truly disadvantaged. In: Jencks, C., Peterson, P.E. (Eds.), The Urban Underclass. The Brookings Institution Press, Washington, DC, pp. 460-483.

Wilson, W.J., 1991b. Studying inner-city dislocations: the challenge of public agenda research. American Sociological Review 56, 1-14.

Woolley, E., Magennis, P., Shokar, P., Lowe, D., Edwards, D., Rogers, S.N., 2006. The correlation between indices of deprivation and health-related quality of life in patients with oral and oropharyngeal squamous cell carcinoma. British Journal of Oral and Maxillofacial Surgery 44, 177-186.

Wu, L.L., Martinson, B.C., 1993. Family structure and the risk of a premarital birth. American Sociological Review 58, 210-232. 
Sooman, A., MacIntyre, S., 1995. Health and perceptions of the local environment in socially contrasting neighbourhoods in Glasgow. Health \& Place 1, 15-26.

South, S.J., Baumer, E.P., 2000. Deciphering community and race effects on adolescent premarital childbearing. Social Focus 78, 1379-1408.

Spencer, M.B., 2001. Resiliency and fragility factors associated with the contextual experiences of low resource urban African American male youth and families. In: Booth, A., Crouter, A. (Eds.), Does it Take a Village? Community Effects in Children, Adolescents and Families. Lawrence Erlbaum Associates, Mahwah, NJ, pp. 51-77.

Steptoe, A., Feldman, P.J., 2001. Neighborhood problems as sources of chronic stress: development of a measure of neighborhood problems, and associations with socioeconomic status and health. Annals of Behavioral Medicine 23, 177-185.

Teenage Pregnancy Unit, 2010. Under 18 Conceptions Statistics 1998-2008. Retrieved July 2010 from 〈http://www.dcsf.gov.uk/everychildmatters/resour ces-and-practice/IG00200/ $\rangle$.

UNICEF, 2001. A League Table of Teenage Births in Rich Nations, Innocenti Report Card no. 3 (vol. 3). UNICEF Innocenti Research Centre, Florence.

Upchurch, D.M., Aneshensal, C.S., Sucoff, C.A., Levy-Storms, L., 1999. Neighborhood and family contexts of adolescent sexual activity. Journal of Marriage and the Family 61, 920-933.

Walsh-Daneshmandi, A., Maclachlan, M., 2000. Environmental risk to the self: factor analysis and development of subscales for the environmental appraisal inventory (EAI) with an Irish sample. Journal of Environmental Psychology 20, 141-149.
Wellings, K., Wadsworth, J., Johnson, A., Field, J., Macdowell, W., 1999. Teenage fertility and life chances. Reviews of Reproduction 4, 184-190.

Wen, M. Hawkley, L.C. Cacioppo, JT., 2006. Objective and perceived neighborhood environment, individual SES and psychosocial factors, and self-rated health: an analysis of older adults in Cook County, Illinois. Social Science \& Medicine 63, 2575-2590.

Westall, J., 1997. Poor education linked with teenage pregnancies. British Medical Journal 314, 535

Wilkinson, R., Pickett, K., 2009. The Spirit Level: Why More Equal Societies Almost Always do Better. Allen Lane, London.

Wilson, M., Daly, M., 1997. Life expectancy, economic inequality, homicide, and reproductive timing in Chicago neighbourhoods. British Medical Journal 314, 1271-1274.

Wilson, W.J., 1991a. Public policy research and the truly disadvantaged. In: Jencks, C., Peterson, P.E. (Eds.), The Urban Underclass. The Brookings Institution Press, Washington, DC, pp. 460-483.

Wilson, W.J., 1991b. Studying inner-city dislocations: the challenge of public agenda research. American Sociological Review 56, 1-14.

Woolley, E., Magennis, P., Shokar, P., Lowe, D., Edwards, D., Rogers, S.N., 2006. The correlation between indices of deprivation and health-related quality of life in patients with oral and oropharyngeal squamous cell carcinoma. British Journal of Oral and Maxillofacial Surgery 44, 177-186.

Wu, L.L., Martinson, B.C., 1993. Family structure and the risk of a premarital birth. American Sociological Review 58, 210-232. 